\title{
LA IRONÎA: ACTOS DE HABLA Y ARGUMENTACIÓN
}

IRONY: SPEECH ACTS AND ARGUMENTATION

\author{
Por Alejandro Ulloa Sanmiguel \\ Profesor Titular \\ Escuela de Comunicación Social \\ Universidad del Valle \\ alejandro.ulloa@correounivalle.edu.co
}

Resumen: El artículo, producto de una investigación sobre el discurso y el lenguaje en la comunicación social, propone una tesis sobre la ironía como un Acto de habla y una forma de argumentación, que igual puede aparecer en la escritura. Apoyado conceptualmente en la teoría de los Actos de habla, se analizan diversos ejemplos en los que se relacionan también la ironía y la metáfora como un modo de ejercer la crítica y expresar las diferencias de opinión.

Palabras Clave: Ironía, Actos de habla, Metáfora, Inferencia, Argumentación.

Abstract: This article, product of an investigation about the speech and the language in the social communication, proposes a thesis about the irony as a speech act and a way to argumentation, that could appear in the writing too. Conceptually supported in the theory of Actos de Habla, are analyzed some examples in which are relationed the irony and the metaphor as a way to criticize and to express the opinion diferences.

Keywords: Irony, speech acts, metaphor, inference, argumentation. 


\section{De "las ironías de la vida" a la ironía como un acto de habla}

Uno de los propósitos de este artículo es analizar la noción de ironía, tal como es utilizada en la comunicación cotidiana donde se pueden identificar dos usos con significados distintos, por lo cual es posible proponer dos tipos de ella. El segundo propósito es reconocer dichos tipos de ironía para describirlos y diferenciarlos a partir de una definición para cada una, y la ilustración de ambas con diversos ejemplos. El tercer propósito es relacionar uno de los tipos de ironía con la teoría de Los actos de habla, para argumentar que la ironía como sarcasmo es un acto de habla. Finalmente, se examina la relación entre este tipo de ironía y la metáfora como una forma de argumentación.

El primer tipo de ironía corresponde a las llamadas "ironías de la vida", aquellas que suceden a diario, en cualquier lugar del mundo, determinadas muchas veces por la historia y otras veces por el azar. Podemos definir esta ironía como el nombre que le damos a ciertas circunstancias de la existencia que se producen en contravía de lo esperado, es decir, que están contra la lógica de lo que debiera ser tenido como normal, o de la expectativa creada, pero que, por alguna razón, terminan convirtiéndose en lo contrario.

Así por ejemplo, es irónico que Osama Bin Laden habiendo sido entrenado por la CIA para combatir a los rusos en Afganistán, se haya convertido, años después, en el enemigo número uno de los Estados Unidos. Esa es una ironía de la vida determinada por las complejas condiciones histórico-sociales de la geopolítica.

En un hecho más elemental, es irónico que un albañil que participa de la construcción del más moderno edificio, viva en un tugurio, pagando el alquiler de una rústica habitación porque no posee una casa para morar. Esa es también una ironía de la vida, determinada por condiciones sociales particulares y concretas.Y es otra ironía el caso del sepulturero que al morir lejos de su pueblo no tenía quien lo sepultara, por ser un viejo solitario, pobre y desconocido en el lugar donde falleció.

Este primer tipo de ironía está de alguna manera representado en varios refranes del habla popular. Entre ellos, los siguientes: "En casa de herrero cuchillo de palo", "Fue por lana y salió trasquilado", "Le salió el tiro por la culata" y "Nadie sabe para quién trabaja". En el primero de ellos, es irónico o paradójico que en la casa de un ingeniero eléctrico no haya tomacorrientes en la pared, los cables estén pelados y se produzcan cortocircuitos que pueden derivar en un incendio.

"Fue por lana y salió trasquilado", puede aplicarse al ciudadano que le reclamó a la Administración de Impuestos la devolución de un dinero porque creyó haber pagado más de lo debido y cuando fue revisado su caso se encontró que debía otros impuestos y debió pagarlos con intereses. En este caso aplica también el dicho: "Le salió el tiro por la culata". 
Para nuestro análisis retomamos el texto de J. Searle, What is a Speech act, ${ }^{1}$ en el que examina y desarrolla la noción de acto ilocutivo, concepto pertinente para establecer la relación con la ironía. Searle plantea un conjunto de "reglas constitutivas" para explicar el acto de prometer y, lo mismo que Austin, considera que el acto ilocutivo no es sólo producto de una intención sino de convenciones sociales que subyacen a la comunicación. Estas condiciones deben complementarse para que el acto ilocutivo sea posible. Si un padre regaña a su hijo tiernamente y riéndose, el regaño no será reconocido como tal, porque la intención de regañarlo no se compagina con la ternura y la risa.

Cuando decimos "mañana te pago", podemos estar haciendo una promesa, pero también es posible que estemos diciendo una mentira. En ambos casos estamos haciendo algo. Y si decimos, “i¿Por qué lo hiciste?!” dependiendo de nuestro interlocutor y del contexto, estamos haciendo un reclamo o un regaño y no solamente una pregunta. Y en la frase "Usted no sabe quién soy yo", se realiza una forma indirecta de intimidación o de amenaza, que puede ser percibida como tal, según el tono con que se diga y el contexto del evento.

En el mismo sentido, la ironía es un acto de habla y una forma de hacer cosas con palabras. Es lo que sucede en el siguiente diálogo entre un ciego y un cojo que se encuentran en el camino. El ciego pregunta al cojo: “¿Cómo anda usted señor?”, y el cojo le responde: "Pues ahí, como usted lo ve...". En los dos interlocutores hay algo de ironía. Pero la pregunta del ciego es una ironía de la vida determinada por el azar, si éste no conoce la condición del cojo; y es una ironía como sarcasmo, si la conoce. Igual, la respuesta del cojo será un sarcasmo si ve o conoce, la ceguera del otro; pero será una ironía determinada por el azar, si no lo sabe, aunque lo tenga en frente.

Ahora bien, desde la teoría de Los actos de habla podemos considerar que la ironía como sarcasmo, corresponde a un acto de habla con sus tres componentes, producto de una intención y unas convenciones sociales subyacentes al significado. Y si admitimos que un acto ilocutivo, descrito también como la fuerza ilocutiva de los enunciados, es lo que se hace con lo que se dice, la ironía es una forma de significar una cosa, diciendo otra.

En el habla, para que se produzca la ironía, es determinante la entonación que acompaña al enunciado, en tanto marca o indicador de la intención; además, puede complementarse con algún gesto, como sucede con la señora que al ver la ropa sucia y sudada de su hijo recién llegado de la escuela, puesta sobre la mesa, a la hora del almuerzo, pregunta 
señalándola: "De quién será esta belleza". Hay en ese enunciado un modo de decir que junto con lo dicho implica una intencionalidad por parte de la madre. La ironía como acto de habla y efecto de significación, surge del reconocimiento por parte del niño, no solo de lo dicho, sino de las marcas de la intención, o sea el tono y el gesto, que acompañan el enunciado.Y estas marcas le permiten interpretar que la madre está usando el término "belleza" en sentido figurado y no en sentido literal, aunque él desconozca estas dos categorías.

La ironía como sarcasmo se define entonces como un acto de habla producido en las interacciones verbales, resultado de una intencionalidad por parte del emisor y unas convenciones sociales que subyacen a la interacción, reconocidas por él y su interlocutor.

Aunque también se pueda producir por medio de una imagen como sucede con la caricatura, la ironía, en tanto acto de habla y efecto de significación, solo es posible cuando el receptor comprende el enunciado, reconoce la intención con que fue dicho, y las convenciones culturales del significado en el contexto del evento comunicativo. (En este caso, el tono de la voz y el uso figurado de la palabra "belleza").

Así, cuando la madre "pregunta", "de quién es esta belleza”, está significando algo distinto a la pregunta literal. Pero al mismo tiempo está haciendo algo con lo dicho: llamar la atención, regañar al niño y sobretodo, ordenarle que quite esa "belleza" de ahí. Mediante una inferencia intuitiva, el chico concluirá que debe quitar la ropa de la mesa pues entiende que la madre sabe de quién es; que además no es ninguna "belleza", sino todo lo contrario y, que por lo tanto, debe retirarla.

Pero, si así funciona la ironía en el habla, en la escritura tiene otra lógica, de la cual no nos ocuparemos teóricamente en este texto dada su complejidad. Para tener una idea, basta citar la frase de Platón en uno de sus Diálogos, cuando afirma preguntando: “¿Sonríes cuando hablas, cómo sonríes en la escritura?”.

\section{La ironía y la metáfora}

Una de las formas de expresar la ironía como sarcasmo es a través de la metáfora, aunque no toda ironía sea metafórica, ni toda metáfora sea irónica. En otras palabras, la relación entre ambas consiste en que la metáfora puede ser una de las formas de construir la ironía, pero no la única, como veremos más adelante.

Si definimos la ironía como sarcasmo, ahora definimos la metáfora como una imagen verbal que condensa el significado en pocas palabras; como una forma de representación que por analogía sustituye a un enunciado mediante asociaciones con las que se puede relacionar. Por otro lado, la ironía como sarcasmo es así mismo una forma de expresar los desacuerdos y puede tener algo de burla, de crítica mordaz, que puede ser hiriente y provocadora, pero también reveladora. En muchos casos, la metáfora puede cumplir las dos funciones a la vez. Un buen ejemplo de ella es la frase metafórica de Monseñor Pedro Rubiano sobre las acusaciones que recaían contra el entonces presidente Ernesto Samper acusado de haber recibido 5 millones de dólares del cartel de Cali, para financiar 
su campaña electoral en los años 90 del siglo pasado. Cuando Samper, acorralado por las evidencias, admitió que si ello ocurrió, "fue a sus espaldas", Monseñor Rubiano ripostó ante los medios: "Eso es como si a uno se le entrara un elefante a la casa y no se diera cuenta”.

Quizás ha sido lo más importante que el entonces arzobispo de Bogotá ha dicho a lo largo de su vida. Una frase corta pero tan certera como una flecha en el blanco. Con ella, Monseñor Rubiano adquirió el estatus de hombre lúcido entre los colombianos. Su declaración, reproducida masivamente por los medios, quedó para la historia. Y no sólo como una frase célebre, sino como la sentencia definitiva que, para muchos, cancelaba cualquier duda sobre las relaciones de Samper con el cartel de Cali. ${ }^{2}$

En el contexto en que fue dicha, para refutar la explicación de Samper, la metáfora del elefante fortalecía las acusaciones en su contra. Una imagen con la que se expresaba una radical diferencia de opinión frente al presidente de la república. Pero a la vez era un acto de habla y una forma de argumentación eficaz. Fijaba un punto de vista claro por parte de un alto jerarca de la iglesia católica, para indicar que no le creía al presidente de Colombia.

La frase era igualmente una crítica sin concesiones a la forma como Samper había ganado las elecciones con el apoyo de la mafia. Con ella, su descrédito fue mayor. Se cumplía así lo que Roland Barthes llamó “el valor heurístico de la metáfora", ${ }^{3}$ es decir, su carácter de epifanía verbal y su capacidad para hacernos comprender con una gran economía de palabras, lo que un largo discurso no siempre consigue. Agregamos aquí el valor multifuncional de la metáfora al decir una cosa y significar otra, al funcionar con eficiencia en distintos niveles de la comunicación y ser reveladora de una idea, o de una verdad, como la sombra, que entre sombras, se convierte en luz.

Se necesita algo más que coraje para manifestar ese desacuerdo públicamente contra un presidente, en un momento crítico para el país y sus instituciones. Desde entonces, el elefante y sus pisadas, persiguen al expresidente Samper, a pesar de que la comisión de acusaciones de la Cámara de Representantes lo declaró inocente. 
Y como el elefante es un animal tan grande y la metáfora es una imagen tan contundente, alcanzó hasta para el presidente Uribe, a quien no sólo le entraron varios elefantes al palacio, uno de ellos llamado Job, sino una manada entera en el congreso. Una manada, con familia extendida, incursionó, como Pedro por su casa, en diferentes instituciones de primer orden: el Das, la Dirección Nacional de Estupefacientes, la Fiscalía de Medellín y hasta en su propia dirección de seguridad con el general Santoyo, "a sus espaldas". Pero por esas ironías de la vida, aunque una manada es mucho más que uno de sus miembros, al presidente Uribe la metáfora del elefante no le hizo tanto daño como a Samper. Tal vez porque había sido utilizada en exceso por los medios de comunicación; o tal vez porque los mismos medios, en su mayoría conniventes con Uribe, prefirieron no usarla para evitar los estragos que causó en el mandato de su antecesor. De todas maneras, al comparar los dos gobiernos, muchos colombianos la evocaron oportunamente.

Ciertas metáforas y algunos actos de habla corresponden a formas inteligentes de expresar los desacuerdos y las diferencias de opinión en público o en privado. De ello hay memorables ejemplos en la historia de la humanidad. Jesucristo era un maestro en el uso de las parábolas (que son semejantes a las metáforas), con las que solía difundir sus ideas, y expresar actos de habla. Cuando los fariseos le pidieron condenar a una prostituta que debía ser apedreada, Jesús les respondió: "El que esté libre de pecado, que tire la primera piedra". Con su respuesta les estaba diciendo "ustedes son tan pecadores como ella” y ningún pecador puede condenar a otro; carece de autoridad moral para hacerlo.

Al igual que Jesucristo, muchos insignes personajes usaron la metáfora y los actos de habla como forma de argumentar, de expresar sus puntos de vista y de ejercer la crítica al orden establecido. Para hacerlo, acudieron a sofisticadas formas de pensamiento y acción con las palabras. Como ya se ha dicho, determinadas metáforas corresponden a formas refinadas de expresar los desacuerdos y las diferencias de opinión. Y como tal, se oponen a las formas burdas y grotescas, o también patéticas, con que suelen expresarse muchos colombianos, al estilo de "Te doy en la cara marica", frase que, al difundirse por televisión, mostró la otra cara del lobo que se viste de oveja. 
Por la elegancia, la sutileza y otras condiciones requeridas, la ironía y la metáfora se oponen también a ciertas prácticas con las que se desconoce al otro y se le ignora en la comunicación, como sucedía con el presidente Uribe cuando algunos periodistas le preguntaban por la relación de su gobierno con el paramilitarismo, y él respondía que la seguridad democrática era un éxito en el país, o que la inversión extranjera había aumentado considerablemente. Como este procedimiento se generalizó al atender a la prensa, pronto se descubrió que allí había también actos de habla, pero de otro calibre: la acción implícita consistía en evadir la pregunta para evitar el compromiso de tener que defender un punto de vista difícilmente sostenible, mediante una argumentación lógica, racional, fundamentada en evidencias y datos verificables que refutaran los indicios en su contra. Rehusarse a responder fue percibido por muchos periodistas no sólo como una burla a sus interrogantes, sino como una afrenta a la opinión pública que pedía explicaciones y debía ser informada objetivamente. El acto de "salirse por la tangente", le evitaba a Uribe responder algunas preguntas sumamente incómodas. Además, le servía para desviar la atención frente a los cuestionamientos cada vez más claros de varios sectores de opinión. Como estrategia de comunicación fríamente calculada, el recurso le funcionó hasta cuando se descubrió en él, una más de las cortinas de humo de su gobierno, seriamente criticado dentro y fuera del país, en medio del amplio respaldo que mostraban las encuestas.

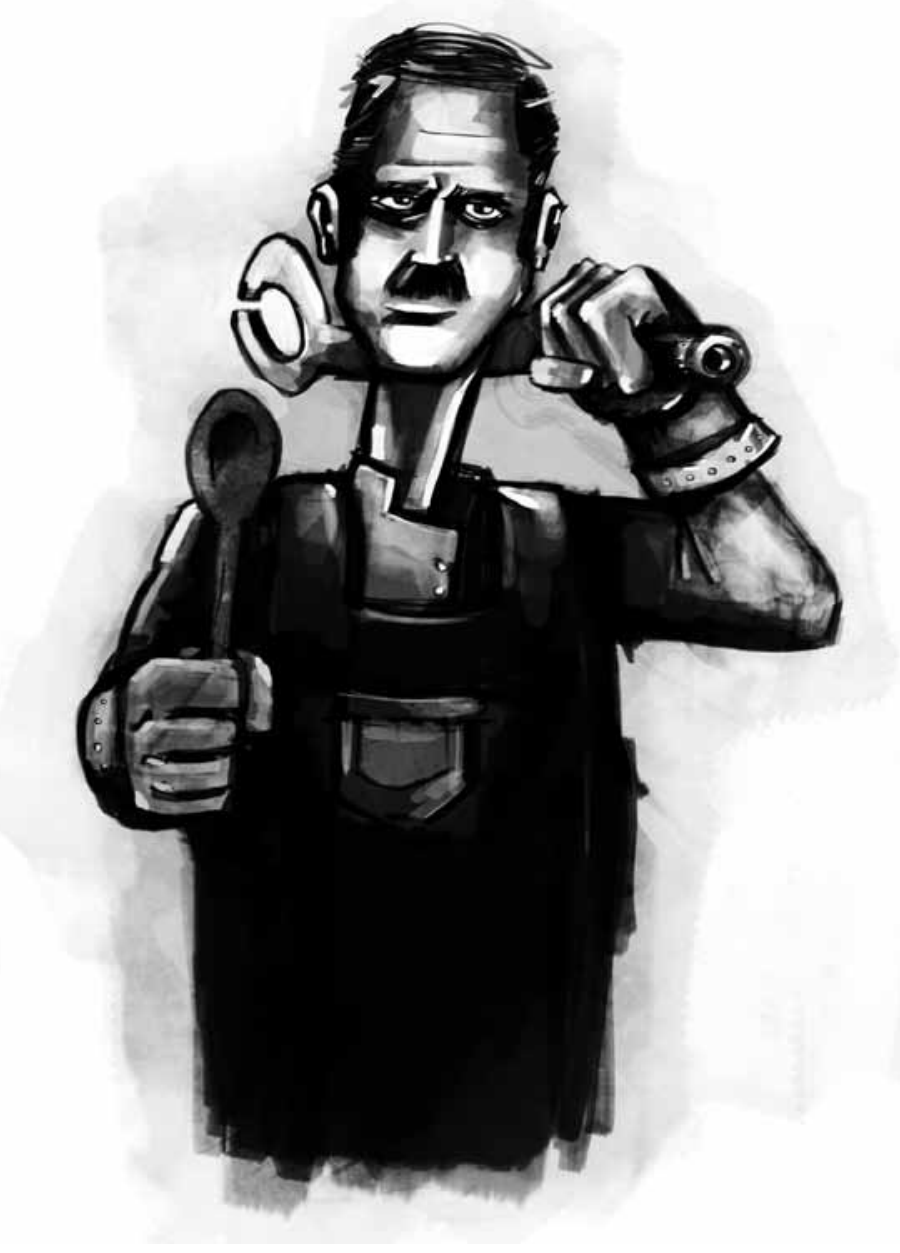

De cualquier manera, dichas estrategias, en cuanto actos de habla, no tuvieron ni la elegancia, ni la gracia de la ironía y la metáfora, ausentes por principio en su lenguaje ordinario, es decir común, y en sus alocuciones presidenciales. En este campo, su logro más alto fue la "metáfora" de "los tres huevitos", una imagen excelsa, comparable sólo con "los pollitos dicen / pío pío pío".

Como se puede inferir, la ironía, a través de la metáfora, es una forma oblicua de realizar la crítica, aunque no toda crítica es necesariamente irónica. Hay una crítica directa cuando se afirma que los colombianos le prestan más atención a los reinados de belleza que a los problemas de la educación en el país. Aquí hay crítica pero no hay ironía. Ironía sería decir que en Colombia no le prestan atención a los reinados de belleza, por atender los problemas de la educación. Pero para que se produzca el efecto de significación que es la ironía, es necesario producir una inferencia, sin la cual no hay ironía, ni crítica posible a través de ella.Y para inferir se requieren conocimientos previos, sin los cuales tampoco es posible la inferencia. Como puede inferirse, los eslabones de la cadena son más de los que parecen. 
Así pues, la comprensión de la ironía nos obliga a considerar muchos aspectos colaterales y factores asociados que aquí apenas insinuamos. De paso, nos asomamos a sus condiciones de producción, para intuir algunas formas de crearla. Una manera de hacerlo sería invirtiendo los términos de una relación, o diciendo las cosas al contrario de lo que en realidad son para que el interlocutor descubra la ironía, como en el ejemplo anterior. O como decía Cantinflas para significar la falta de educación, diciendo: "La falta de ignorancia". Otro modo, muy parecido, consiste en atribuirle a un objeto las virtudes que no tiene. Por ejemplo, si hablamos de la gran poesía que hay en el reguetón al estilo de "Perrea mami perrea", "Metelo papi metelo" o "Con la luz apagá, eso en cuatro no se vé". Versos tan sublimes como la imagen de "los tres huevitos" y "los pollitos dicen...".

Uno más consiste en poner las palabras entre comillas, tal como aparece la palabra "metáfora" en un párrafo anterior; aunque no siempre las comillas indiquen o marquen la ironía, porque también se usan para citar literalmente el discurso de alguien en un texto, o en el habla.

Como puede verse, he propuesto una reflexión personal y un punto de vista sobre la ironía, apoyándome conceptualmente en algunas teorías linguísticas, ilustrando el análisis con ejemplos reales, acordes con la argumentación desplegada. Y por supuesto, escribiendo con algo de ironía también, porque sería muy irónico que un artículo sobre la ironía no lo hiciera. No valdría la pena escribirlo.

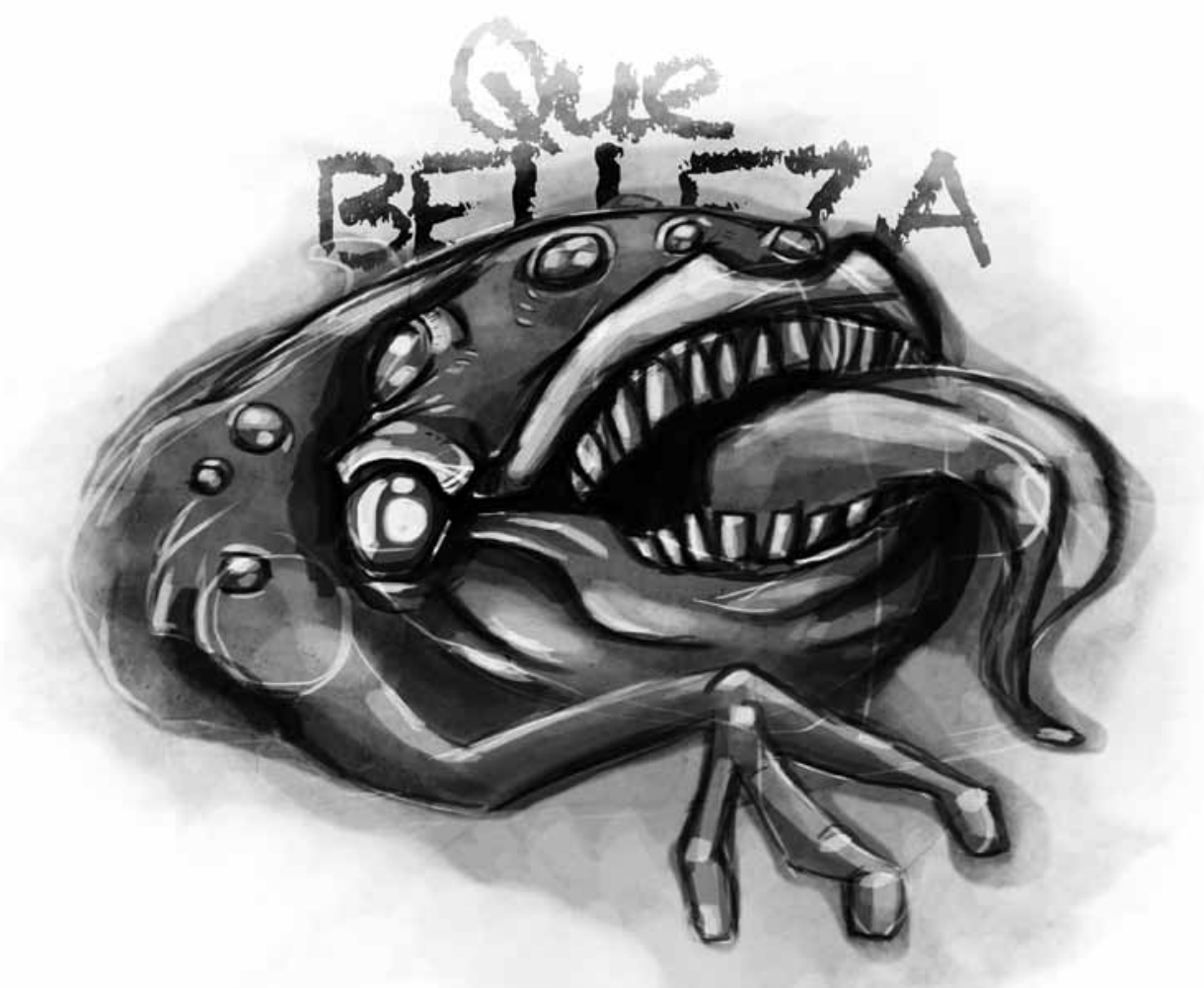


${ }^{1}$ Usamos como referencia la traducción hecha por la profesora Gabriela Castellanos, bajo el nombre ¿"Qué es un acto de habla"?, publicada en el libro Lenguaje y Sociedad, por el Centro de Traducciones Universidad del Valle, Cali 1983. Págs. 79 -99.

${ }^{2}$ El caso del presidente Samper involucrado en "El Proceso ocho mil", incluyó a varios congresistas del Valle del Cauca, personajes de la prensa y la farándula local y otros funcionarios del gobierno. Fue el escándalo más importante de corrupción en Colombia al finalizar el siglo XX, sólo superado, 15 años después, por la actual "Parapolítica".

${ }^{3}$ R. Barthes, en "Retórica de la Imagen”- Págs. 29 - 47

${ }^{4}$ Ver Noticias Uno, en http://www.youtube.com/atch?v=QjT2OONKmZ0

\section{Referencias}

Austin, J L. (1982). Cómo hacer cosas con palabras: Palabras y acciones (How to Do Things withWords). Barcelona: Paidós.

Barthes, Roland. (1986). Retórica de la Imagen. En Lo obvio y lo obtuso, imágenes, gestos, voces, Paidós Comunicación.

Ducrot, Oswald. (1984). El decir y lo dicho, Librería el Hachete. (1994). Polifonía y Argumentación, Universidad del Valle, Escuela de Ciencias del Lenguaje.

Ducrot, Oswald y Todorov, Tzvetan. (1981). Diccionario enciclopédico de las ciencias del lenguaje. Siglo XXI Editores, México.

Searle, John R. (1983). ¿Qué es un acto de habla? En Lenguaje y Sociedad Centro de Traducciones Universidad del Valle, Cali.

Recibido: marzo 30 / Aprobado: mayo 27 de 2013 